\section{RMD Open}

Rheumatic \&

Musculoskeletal Diseases

\title{
Association of erythrocyte methotrexate- polyglutamate levels with the efficacy and hepatotoxicity of methotrexate in patients with rheumatoid arthritis: a 76-week prospective study
}

To cite: Takahashi C, Kaneko Y, Okano Y, et al. Association of erythrocyte methotrexate-polyglutamate levels with the efficacy and hepatotoxicity of methotrexate in patients with rheumatoid arthritis: a 76week prospective study. $R M D$ Open 2017;3:e000363. doi:10.1136/rmdopen-2016000363

- Prepublication history and additional material is available. To view please visit the journal (http://dx.doi.org/ 10.1136/rmdopen-2016000363).

Received 12 September 2016 Revised 4 November 2016 Accepted 4 December 2016

CrossMark

For numbered affiliations see end of article.

Correspondence to Dr Tsutomu Takeuchi; tsutake@keio.jp

\section{ABSTRACT}

Objective: To assess the utility of erythrocyte methotrexate-polyglutamate (MTX-PG) concentrations in determining the safety and efficacy of MTX in patients with rheumatoid arthritis (RA).

Methods: 79 MTX-naïve patients with RA were enrolled in this prospective 76-week cohort study. MTX was initiated, and a predefined dose-escalation protocol was followed. Erythrocyte MTX-PG concentrations were measured using liquid chromatography. The associations of MTX-PG concentrations with disease activity and adverse events were analysed.

Results: Dose escalation of MTX resulted in increased MTX-PG concentrations and a decrease in the mean Disease Activity Score in 28 joints (DAS28).

A significant association was observed between total MTX-PG concentrations and $\triangle \mathrm{DAS} 28$ at week 12 $(\beta=-0.013, p=0.003)$ and at week $24(\beta=-0.014$, $p=0.003$ ). The maximum MTX-PG levels were significantly higher in patients presenting with elevated transaminases $(\geq 100 \mathrm{lU} / \mathrm{L})$ than in those without (146 vs $106 \mathrm{nmol} / \mathrm{L}, \mathrm{p}=0.009$ ). Receiver operating characteristic curve analysis revealed that a total MTX-PG concentrations of $83 \mathrm{nmol} / \mathrm{L}$ at week 12 was the threshold for a DAS28 improvement of $\geq 1.2$ at week 24 , and $105 \mathrm{nmol} / \mathrm{L}$ was the threshold for transaminases of $\geq 50 \mathrm{IU} / \mathrm{L}$ and $131 \mathrm{nmol} / \mathrm{L}$ for transaminases of $\geq 100 \mathrm{IU} / \mathrm{L}$. MTX-PG concentrations were strongly influenced by body mass index and a serum albumin level.

Conclusions: MTX-PG concentrations are a useful biomarker in MTX therapy, in terms of efficacy and safety.

\section{INTRODUCTION}

Methotrexate (MTX) is the mainstay of disease-modifying anti-rheumatic drug (DMARD) therapy. It is widely used to treat rheumatoid arthritis (RA) because of its

\section{Key messages}

What is already known about this subject?

- Risk factors underlying the interpatient variability in the response to methotrexate (MTX) in patients with rheumatoid arthritis have been unclear.

- While plasma MTX concentrations fall below pharmacologically effective levels rapidly, MTXpolyglutamates (MTX-PGs) retained within the cells for a period of time might be a potential biomarker associated with response to MTX.

What does this study add?

- This long-term multicentre prospective study assessed the relationship between the dynamics of intraerythrocyte MTX-PG concentrations and the efficacy and adverse effects of MTX in patients with rheumatoid arthritis.

How might this impact on clinical practice?

- Monitoring MTX-PGs could optimise treatment response while minimising liver injury in the treatment with MTX.

- The body mass index and the serum albumin level affected MTX-PG concentrations.

marked efficacy and acceptable side effect profile. ${ }^{1}$ However, a number of patients have a poor response despite dose escalation, or experience adverse events resulting in dose restriction or treatment cessation. At present, the mechanisms and risk factors underlying the interpatient variability in the response to MTX have not been established. However, the amount of MTX or MTX metabolites in the body could be a major determinant of its effect.

MTX is transported into cells via a reduced folate carrier, where it is converted by 
folylpolyglutamate synthase into glutamate-chained MTX. It is retained within the cells for a period of time after its elimination from the plasma. Depending on the number of conjugated glutamates, MTX-polyglutamates (MTX-PGs) can be present as MTX-PG1 through 5. MTX-PGs inside the cells increase the inhibition of de novo purine synthesis and promote the accumulation of adenosine, thereby exerting immunosuppressive and anti-inflammatory effects. ${ }^{2-4}$

Plasma MTX concentrations fall below pharmacologically effective levels rapidly. ${ }^{5}$ Therefore, they are unreliable for predicting the efficacy or toxicity of MTX in patients with RA. ${ }^{6-12}$ In contrast, MTX-PG concentrations in erythrocytes have been identified as a potentially promising biomarker associated with response to MTX in patients with RA and juvenile idiopathic arthritis. ${ }^{12-17}$ However, the majority of these studies employed a crosssectional design, and reported conflicting results on the efficacy and limited findings on the safety of MTX in relation to MTX-PG concentrations.

The aim of this long-term multicentre prospective study was to clarify the association between the dynamics of intraerythrocyte MTX-PG concentrations and the efficacy and adverse effects of MTX in patients with RA.

\section{METHODS}

\section{Study protocol and patients}

The MAGIK (methotrexate as an anchor drug in Japanese rheumatoid arthritis monitored by erythrocyte PG concentrations at the Keio Rheumatology Expert Meeting) study, which was a 76-week long multicentre prospective study, started in December 2012. The medical ethics committee at each study site approved the protocol prior to study initiation, and all patients gave written informed consent before enrolment. This study was registered with the University Hospital Medical Information Network (UMIN000008514).

We enrolled patients in whom RA had been diagnosed according to the 2010 American College of Rheumatology (ACR)/European League Against Rheumatism (EULAR) classification criteria. ${ }^{18}$ These patients also had to have active disease (Disease Activity Score in 28 joints (DAS28)>3.2), be naive to MTX or biological agent therapy, and be scheduled to start MTX treatment for their RA. Patients who were contraindicated to MTX, had a desire to bear a child, or had serious complications were excluded.

The study protocol specified the dose-escalation procedure for MTX, as well as the time points for performing clinical assessments including disease activity and adverse events and measuring MTX-PG concentrations. MTX was started at a dose of $8 \mathrm{mg} /$ week with $5 \mathrm{mg} /$ week folic acid, and was increased by $4 \mathrm{mg}$ every 4 weeks until $16 \mathrm{mg}$ /week, the maximum dose allowed in Japan, had been reached. Adding other DMARDs during the study was not allowed. This protocol was followed unless the patient achieved remission or experienced relevant adverse events. The dose could be decreased if adverse events occurred. The patients' clinical and biochemical parameters were assessed at baseline and at weeks 4,8 , $12,24,36,52$ and 76 of the study.

\section{Clinical parameters}

Data on patient demographics and clinical characteristics were obtained. This included age, sex, duration of arthritic symptoms, smoking status, body mass index (BMI), DAS28, Health Assessment Questionnaire Disability Index score (HAQ-DI), rheumatoid factor, anti-cyclic citrullinated peptide antibody, estimated glomerular filtration rate (eGFR) calculated with the Cockroft-Gault formula, aspartate transaminase (AST) levels, alanine transaminase (ALT) levels and blood cell counts. Hepatotoxicity was defined as AST or ALT $>50 \mathrm{IU} / \mathrm{L}$, and leucopenia was defined as white cell count $<3000 / \mu \mathrm{L}$. Outcome measures for effectiveness of MTX were $\triangle$ DAS28, EULAR good response, ${ }^{19}$ DAS28 remission $^{20}$ and $\triangle \mathrm{HAQ}$-DI.

\section{MTX-PG concentrations}

To measure the MTX-PG concentrations, blood samples were collected in EDTA tubes at prespecified clinical assessment visits. The EDTA tube was centrifuged for $5 \mathrm{~min}$ at $3000 \mathrm{rpm}$ at $4^{\circ} \mathrm{C}$. The cell pellet was collected and centrifuged again after the addition of isotonic saline. The resulting packed red blood cells were stored at $-80^{\circ} \mathrm{C}$. These samples were air-shipped under dry ice to Exagen Diagnostics (Vista, California, USA), and the MTX-PGs (MTX-PG1, MTX-PG2, MTX-PG3, MTX-PG4 and MTX-PG5) were measured using a liquid chromatography-electrospray ionisation tandem mass spectrometry-based assay as previously described. ${ }^{21}$ The total MTX-PGs, or the sum of MTX-PG1 through MTX-PG5, was used in the analysis.

\section{Statistical analysis}

The comparison of proportions and correlations between groups was tested with Student's t-test, $\chi^{2}$ test, Mann-Whitney U-test, Spearman's correlation coefficient, and one-way analysis of variance, in accordance with the type of variable. Cross-sectional analyses of the association of MTX-PGs with the $\triangle \mathrm{DAS} 28$ were performed with a linear mixed model with correction by potential confounders including age, non-steroidal antiinflammatory drug (NSAID) use, the use of other DMARDs, glucocorticoid use, smoking status and eGFR. Cut-off MTX-PG concentrations with optimal sensitivity and specificity for predicting the decrease in DAS28 of more than 1.2, or the increase in transaminases of $\geq 50$ or $100 \mathrm{IU} / \mathrm{L}$, was determined using receiver operating characteristic (ROC) curves. A two-sided statistical test of no difference at the $5 \%$ significance level was used. All statistical analyses were performed using SPSS V.23.0 (SPSS, Chicago, Illinois, USA). 
RESULTS

\section{Patient characteristics}

A total of 79 patients were included in the study. Table 1 shows the baseline characteristics of the patients enrolled. The mean age was 56.7 years, and the majority of patients were female $(86 \%)$. The mean BMI was $21.9 \mathrm{~kg} / \mathrm{m}^{2}$, which was around the average for Japanese individuals. The mean DAS28 was 4.0 at baseline.

\section{Pharmacokinetics of MTX-PG in erythrocytes and disease activity}

Figure 1A shows the pharmacokinetics of the total MTX-PGs and fractions of MTX-PGs in erythrocytes with the mean dose of MTX from baseline through 76 weeks. MTX-PGs were measured in 79 patients at week 4, 78 patients at week 8,76 patients at week 12,51 patients at week 24,43 patients at week 36,37 patients at week 52 , and 35 patients at week 76 . The attrition was due to various patient-related factors, including 2 moving house, 3 missing a blood test, 9 being lost to follow-up, 5 to adverse events, 23 to use of biological agents, or 2 withdrawing consent. Total MTX-PG values increased steadily with MTX dose-escalation and plateaued after 12 weeks at $\sim 90 \mathrm{nmol} / \mathrm{L}$ on $10.5 \mathrm{mg} /$ week of MTX. The main fractions of MTX-PGs were MTX-PG1 and MTX-PG2, followed by MTX-PG3. MTX-PG4 and MTX-PG5 were nearly undetectable throughout the 76 weeks.

Figure 1B demonstrates the mean DAS28 which decreased from 4.0 at baseline to 3.3 at week $4,2.7$ at week $8,2.6$ at week $12,2.0$ at week $24,1.9$ at week 36 , 1.7 at week 52, and to 1.5 at week $76(\mathrm{p}<0.05$ at all time points compared with the baseline).

Table 1 Demographic and clinical characteristics

\begin{tabular}{lc}
\hline Characteristics (N=79) & Mean (SD) \\
\hline Age (year) & $56.7(14.7)$ \\
Woman (n, \%) & $68(86)$ \\
Body mass index & $21.9(3.3), \mathrm{N}=74$ \\
Current smoker (n, \%) & $19(24)$ \\
Symptom duration before MTX start & $2.2(5.7)$ \\
(month) & \\
Anti-CCP positive (n, \%) & $53(67)$ \\
RF positive (n, \%) & $66(85)$ \\
DAS28 & $4.0(1.1)$ \\
HAQ-DI & $0.894(1.009)$ \\
AST (IU/mL) & $19(5)$ \\
ALT (IU/mL) & $16(8)$ \\
eGFR (mL/min) & $88(26)$ \\
Other DMARDs use (n, \%) & $7(9)$ \\
Glucocorticoid use (n, \%) & $6(8)$ \\
NSAID use (n, \%) & $27(34)$ \\
\hline ALT, alanin transaminase; Anti-CCP, anti-cyclic
\end{tabular}

$\mathrm{ALT}$, alanine transaminase; Anti-CCP, anti-cyclic citrullinated peptide; AST, aspartate transaminase; DAS28, Disease Activity Score for 28 joints; DMARDs, disease-modifying anti-rheumatic drugs; eGFR, estimated glomerular filtration rate; HAQ-DI, Health Assessment Questionnaire Disability Index; MTX, methotrexate; NSAID, non-steroid anti-inflammatory drug; RF, rheumatoid factor.
Association of MTX-PG concentration with clinical effectiveness

Table 2 shows the results of cross-sectional analyses with a linear mixed modelling for association between MTX-PG levels with $\triangle \mathrm{DAS28}$ at the corresponding visit. A significant association with $\triangle \mathrm{DAS} 28$ was observed for MTX-PG3 $(\beta=-0.035 ; \mathrm{SE}=0.017 ; \mathrm{p}=0.04)$ at week 8; MTX-PG1 $(\beta=-0.025 ; \quad \mathrm{SE}=0.007 ; \quad \mathrm{p}=0.000), \quad$ MTX-PG2 $(\beta=-0.035 ; \quad \mathrm{SE}=0.011 ; \quad \mathrm{p}=0.002)$ and total MTX-PG $(\beta=-0.013 ; \mathrm{SE}=0.004 ; \mathrm{p}=0.003)$ at week 12; MTX-PG1 $(\beta=-0.026 ; \mathrm{SE}=0.009 ; \mathrm{p}=0.005)$, MTX-PG2 $(\beta=-0.027$; $\mathrm{SE}=0.012 ; \mathrm{p}=0.03)$, MTX-PG3 $(\beta=-0.028 ; \mathrm{SE}=0.014 ; \mathrm{p}=0.04)$ and total MTX-PG $(\beta=-0.014 ; \mathrm{SE}=0.004 ; \mathrm{p}=0.003)$ at week 24; and for MTX-PG3 ( $\beta=-0.03$; $\mathrm{SE}=0.015$; $\mathrm{p}=0.04)$ at week 36. Furthermore, MTX-PG levels at week 12, the time when the concentrations reached a plateau, were associated with $\triangle \mathrm{DAS} 28$ at weeks 24 and 36; MTXPG1 $(\beta=-0.025 ; \mathrm{SE}=0.010 ; p=0.01)$, MTX-PG2 $(\beta=-0.067$; $\mathrm{SE}=0.013 ; \quad \mathrm{p}=0.000), \quad$ MTX-PG3 $\quad(\beta=-0.039 ; \quad \mathrm{SE}=0.018$; $\mathrm{p}=0.04)$ and total MTX-PG $(\beta=-0.018 ; \quad \mathrm{SE}=0.004 ;$ $\mathrm{p}=0.001)$ at week 24; MTX-PG1 $(\beta=-0.031 ; \mathrm{SE}=0.008$; $\mathrm{p}=0.001)$, MTX-PG2 $(\beta=-0.051 ; \mathrm{SE}=0.016 ; \mathrm{p}=0.002)$ and total MTX-PG $(\beta=-0.016 ; \mathrm{SE}=0.005 ; \mathrm{p}=0.001)$ at week 36 .

The associations of MTX-PG concentrations with other outcome measures including EULAR good response, DAS28 remission and $\triangle \mathrm{HAQ}-\mathrm{DI}$ are tabulated in tables 3 and 4. At weeks 12 and 24, MTX-PG concentrations were significantly higher in the patients who achieved EULAR good response or DAS28 remission than in those who did not. $\triangle$ HAQ-DI were associated with MTX-PG concentrations at weeks 24 and 36 by a linear mixed modelling.

ROC analysis was used to determine the cut-off concentrations of total MTX-PGs at week 12 needed to produce an improvement of $>1.2$ in DAS28 at week 24 (figure 1C). A total MTX-PG concentration of $\geq 83.3 \mathrm{nmol} / \mathrm{L}$ could discriminate between patients with a DAS28 improvement of $\geq 1.2$ and those without; the area under the curve (AUC) for this was $0.72(95 \%$ CI 0.57 to $0.87, \mathrm{p}=0.02$ ).

\section{Adverse events}

Over a period of 76 weeks, 27 patients (34.2\%) reported 46 instances of adverse events. Twenty patients (25.3\%) presented with gastrointestinal symptoms, including nausea and stomatitis; $20(25.3 \%)$ with hepatotoxicity (defined as AST or ALT $\geq 50 \mathrm{IU} / \mathrm{L}$, the same patients with $\mathrm{ALT} \geq 50 \mathrm{IU} / \mathrm{L}$ in consequence); 2 (2.5\%) with leucopenia; 1 (1.3\%) with hair loss; 1 (1.3\%) with Pneumocystis jirovecii pneumonia; 1 (1.3\%) with cryptococcal pneumonia; and $1(1.3 \%)$ with malignancy (gastric cancer). The last three events were deemed to be serious adverse events.

Among the 20 patients who developed hepatotoxicity, 12 had transaminase levels exceeding 100. The maximum total MTX-PG levels were $105.6 \mathrm{nmol} / \mathrm{L}$ in patients without hepatotoxicity, $119.5 \mathrm{nmol} / \mathrm{L}$ in those with $50 \leq \mathrm{AST} / \mathrm{ALT}<100$, and $146.3 \mathrm{nmol} / \mathrm{L}$ in those with 
A

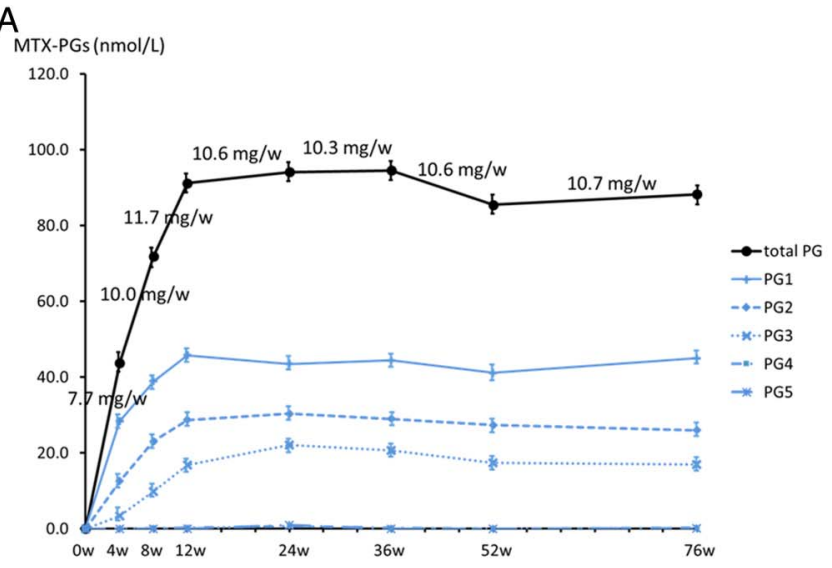

B

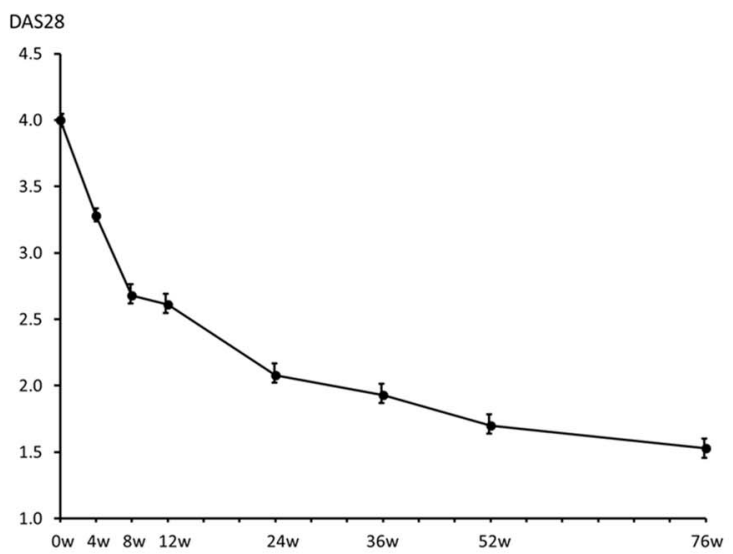

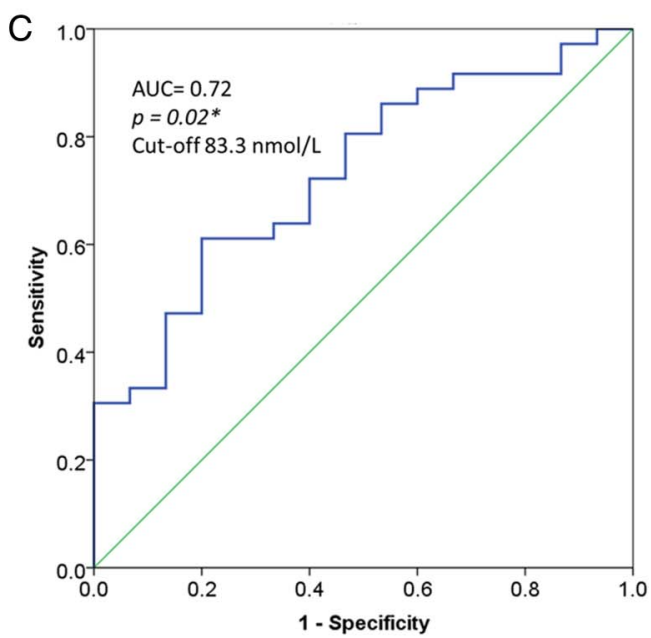

Figure 1 MTX-PG concentrations and efficacy. (A) Pharmacokinetics of MTX-PG concentrations with the mean MTX dose; (B) DAS28 and (C) cut-off values at week 12 for $\triangle \mathrm{DAS} 28>1.2$ at week 24. ${ }^{*} \mathrm{p}<0.05$. AUC, area under the curve; DAS28, Disease Activity Score for 28 joints; MTX-PG, methotrexate polyglutamate.

Table 2 Cross-sectional analysis of MTX-PG concentrations and $\triangle \mathrm{DAS} 28$ with a linear mixed model

\begin{tabular}{|c|c|c|c|c|c|c|c|}
\hline & Week 4 & Week 8 & Week 12 & Week 24 & Week 36 & Week 52 & Week 76 \\
\hline MTX-PG1 & $\begin{array}{l}0.018 \\
(0.011) \\
p=0.11\end{array}$ & $\begin{array}{l}-0.003 \\
(0.008) \\
p=0.68\end{array}$ & $\begin{array}{l}-0.025 \\
(0.007)^{*} \\
p=0.000\end{array}$ & $\begin{array}{l}-0.026 \\
(0.009)^{\star} \\
p=0.005\end{array}$ & $\begin{array}{l}-0.013 \\
(0.010) \\
p=0.022\end{array}$ & $\begin{array}{l}-0.008 \\
(0.015) \\
p=0.59\end{array}$ & $\begin{array}{l}0.009 \\
(0.013) \\
p=0.49\end{array}$ \\
\hline MTX-PG2 & $\begin{array}{l}0.018 \\
(0.016) \\
p=0.27\end{array}$ & $\begin{array}{l}-0.002 \\
(0.013) \\
p=0.86\end{array}$ & $\begin{array}{l}-0.035 \\
(0.011)^{\star} \\
p=0.002\end{array}$ & $\begin{array}{l}-0.027 \\
(0.012)^{\star} \\
p=0.03\end{array}$ & $\begin{array}{l}-0.023 \\
(0.016) \\
p=0.15\end{array}$ & $\begin{array}{l}-0.013 \\
(0.017) \\
p=0.45\end{array}$ & $\begin{array}{l}0.021 \\
(0.022) \\
p=0.35\end{array}$ \\
\hline MTX-PG3 & $\begin{array}{l}0.019 \\
(0.026) \\
p=0.48\end{array}$ & $\begin{array}{l}-0.035 \\
(0.017)^{\star} \\
p=0.04\end{array}$ & $\begin{array}{l}-0.023 \\
(0.013) \\
p=0.07\end{array}$ & $\begin{array}{l}-0.028 \\
(0.014)^{\star} \\
p=0.04\end{array}$ & $\begin{array}{l}-0.030 \\
(0.015)^{\star} \\
p=0.04\end{array}$ & $\begin{array}{l}-0.006 \\
(0.020) \\
p=0.76\end{array}$ & $\begin{array}{l}0.005 \\
(0.022) \\
p=0.83\end{array}$ \\
\hline $\begin{array}{l}\text { Total } \\
\text { MTX-PG }\end{array}$ & $\begin{array}{l}0.008 \\
(0.006) \\
p=0.19\end{array}$ & $\begin{array}{l}-0.003 \\
(0.005) \\
p=0.41\end{array}$ & $\begin{array}{l}-0.013 \\
(0.004)^{\star} \\
p=0.003\end{array}$ & $\begin{array}{l}-0.014 \\
(0.004)^{*} \\
p=0.003\end{array}$ & $\begin{array}{l}-0.009 \\
(0.005) \\
p=0.09\end{array}$ & $\begin{array}{l}-0.005 \\
(0.007) \\
p=0.43\end{array}$ & $\begin{array}{l}0.006 \\
(0.007) \\
p=0.41\end{array}$ \\
\hline
\end{tabular}

Upper: $\beta$, SE.

Lower: $p$.

${ }^{*} \mathrm{p}<0.05$.

DAS28, Disease Activity Score for 28 joints; MTX-PG, methotrexate polyglutamate.

AST $/$ ALT $\geq 100 \quad(p=0.009$, figure 2A). ROC analysis determined the cut-off value of MTX-PG concentrations for AST/ALT elevation $\geq 50 \mathrm{IU} / \mathrm{L}$ to be $105.4 \mathrm{nmol} / \mathrm{L}$ with an AUC of 0.67 (95\% CI 0.52 to $0.81, \mathrm{p}=0.03$, figure $2 \mathrm{~B}$ ), and that for AST/ALT $\geq 100 \mathrm{IU} / \mathrm{L}$ to be $131.0 \mathrm{nmol} / \mathrm{L}$ (95\% CI 0.50 to $0.93, \mathrm{p}=0.04$, figure $2 \mathrm{C}$ ). Of note, NSAIDs use and other DMARDs use were not different between the patients with AST/ALT $\geq 50 \mathrm{IU} / \mathrm{L}$ 
Table 3 Associations of MTX-PG concentrations with EULAR good response, DAS28 remission and $\triangle H A Q-D I$

\begin{tabular}{|c|c|c|c|c|c|c|c|c|c|}
\hline & $\mathbf{N}$ & $\begin{array}{l}\text { MTX-PG1 } \\
\text { (nmol/L) }\end{array}$ & p Value & $\begin{array}{l}\text { MTX-PG2 } \\
\text { (nmol/L) }\end{array}$ & p Value & $\begin{array}{l}\text { MTX-PG3 } \\
\text { (nmol/L) }\end{array}$ & p Value & $\begin{array}{l}\text { Total MTX-PG } \\
\text { (nmol/L) }\end{array}$ & p Value \\
\hline \multicolumn{10}{|l|}{ Week 4} \\
\hline Remission (+) & 23 & 27.1 & 0.51 & 11.8 & 0.58 & 3.1 & 0.75 & 41.3 & 0.48 \\
\hline Remission (-) & 56 & 28.9 & & 12.9 & & 3.4 & & 44.8 & \\
\hline Good response (+) & 18 & 27.9 & 0.85 & 14.6 & 0.19 & 5.1 & 0.46 & 46.6 & 0.50 \\
\hline Good response (-) & 61 & 28.5 & & 11.9 & & 4.8 & & 42.9 & \\
\hline$\triangle \mathrm{HAQ}, \beta(\mathrm{SE})$ & 79 & $-0.002(0.006)$ & 0.68 & $0.004(0.009)$ & 0.49 & $0.003(0.014)$ & 0.7 & $-0.002(0.003)$ & 0.95 \\
\hline \multicolumn{10}{|l|}{ Week 8} \\
\hline Remission (+) & 33 & 40.7 & 0.25 & 22.8 & 8.3 & 10.4 & 0.40 & 71.2 & 0.85 \\
\hline Remission (-) & 45 & 36.9 & & 23.3 & & 9.1 & & 72.3 & \\
\hline Good response (+) & 33 & 38.8 & 0.97 & 22.0 & 0.39 & 10.4 & 0.52 & 71.2 & 0.85 \\
\hline Good response (-) & 45 & 39.0 & & 23.8 & & 9.4 & & 72.3 & \\
\hline$\Delta \mathrm{HAQ}, \beta$ (SE) & 78 & $0.001(0.005)$ & 0.11 & $0.002(0.008)$ & 0.24 & $-0.011(0.011)$ & 0.29 & $-0.000(0.003)$ & 0.93 \\
\hline \multicolumn{10}{|l|}{ Week 12} \\
\hline Remission (+) & 46 & 50.4 & $0.02^{*}$ & 30.5 & 0.14 & 16.9 & 0.87 & 97.3 & 0.09 \\
\hline Remission (-) & 30 & 40.6 & & 26.7 & & 16.6 & & 84.3 & \\
\hline Good response (+) & 39 & 51.1 & $0.007^{\star}$ & 32.2 & $0.004^{*}$ & 18.8 & 0.08 & 101.1 & $0.001^{*}$ \\
\hline Good response (-) & 37 & 40.1 & & 24.9 & & 14.6 & & 75.9 & \\
\hline$\Delta \mathrm{HAQ}, \beta$ (SE) & 76 & $-0.009(0.005)$ & 0.08 & $-0.005(0.008)$ & 0.05 & $-0.011(0.008)$ & 0.23 & $-0.004(0.003)$ & 0.11 \\
\hline \multicolumn{10}{|l|}{ Week 24} \\
\hline Remission (+) & 35 & 48.7 & $0.03^{*}$ & 34.6 & $0.02^{*}$ & 24.7 & 0.09 & 109.1 & $0.001^{*}$ \\
\hline Remission (-) & 14 & 34.9 & & 23.2 & & 17.4 & & 66.4 & \\
\hline Good response (+) & 37 & 35.2 & $0.05^{\star}$ & 33.9 & $0.04^{*}$ & 23.4 & 0.50 & 102.1 & 0.11 \\
\hline Good response (-) & 12 & 27.9 & & 23.4 & & 20.3 & & 80.8 & \\
\hline$\Delta \mathrm{HAQ}, \beta$ (SE) & 49 & $-0.015(0.006)$ & $0.02^{*}$ & $-0.018(0.008)$ & $0.04^{*}$ & $-0.019(0.010)$ & 0.07 & $-0.008(0.003)$ & $0.02^{*}$ \\
\hline \multicolumn{10}{|l|}{ Week 36} \\
\hline Remission (+) & 37 & 46.4 & 0.18 & 30.2 & 0.32 & 21.7 & 0.48 & 98.8 & 0.22 \\
\hline Remission (-) & 5 & 33.7 & & 24.3 & & 17.6 & & 75.6 & \\
\hline Good response (+) & 33 & 46.1 & 0.46 & 30.4 & 0.41 & 22.6 & 0.16 & 99.3 & 0.25 \\
\hline Good response (-) & 9 & 40.5 & & 26.5 & & 16.2 & & 83.9 & \\
\hline$\triangle \mathrm{HAQ}, \beta$ (SE) & 42 & $-0.012(0.009)$ & 0.19 & $-0.020(0.014)$ & 0.17 & $-0.038(0.016)$ & $0.03^{*}$ & $-0.014(0.006)$ & $0.03^{\star}$ \\
\hline \multicolumn{10}{|l|}{ Week 52} \\
\hline Remission (+) & 32 & 39.8 & 0.07 & 27.6 & 0.72 & 16.8 & 0.18 & 84.0 & 0.13 \\
\hline Remission (-) & 4 & 55.9 & & 30.1 & & 25.0 & & 111.0 & \\
\hline Good response (+) & 28 & 39.9 & 0.24 & 27.0 & 0.46 & 17.7 & 0.08 & 84.2 & 0.31 \\
\hline Good response (-) & 8 & 47.8 & & 30.8 & & 18.0 & & 96.7 & \\
\hline \multirow[t]{2}{*}{$\Delta \mathrm{HAQ}, \beta$ (SE) } & 36 & $-0.026(0.014)$ & 0.07 & $-0.016(0.017)$ & 0.33 & $-0.006(0.020)$ & 0.76 & $-0.005(0.007)$ & 0.43 \\
\hline & & & & & & & & & Continued \\
\hline
\end{tabular}

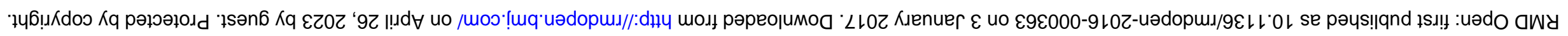




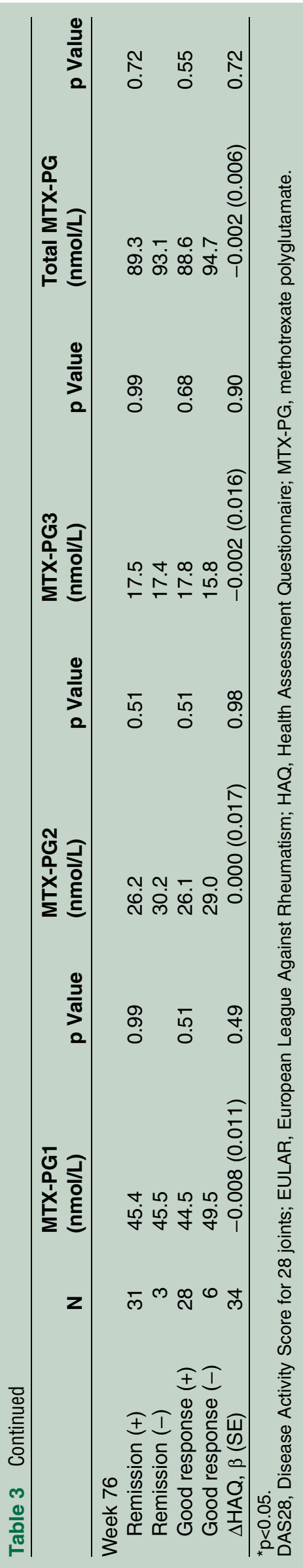

Table 4 Correlations of baseline factors with total MTX-PGs at weeks 12 and 24

\begin{tabular}{lcc}
\hline & 12 weeks & 24 weeks \\
\hline Age & 0.008 & -0.011 \\
& 0.94 & 0.94 \\
Body weight & -0.205 & -0.305 \\
& 0.08 & $0.03^{*}$ \\
Body mass index & -0.318 & -0.422 \\
& $0.006^{*}$ & $0.002^{*}$ \\
White blood count & 0.192 & 0.239 \\
& 0.10 & 0.09 \\
Red blood count & -0.116 & -0.137 \\
& 0.32 & 0.34 \\
Serum albumin & -0.146 & -0.364 \\
& 0.22 & $0.01^{*}$ \\
eGFR & -0.038 & 0.061 \\
& 0.75 & 0.67 \\
\hline Upper: $\rho$. & & \\
Lower: $p$. & & \\
*p<0.05. & & \\
eGFR, estimated glomerular filtration rate; MTX-PG, methotrexate \\
polyglutamates.
\end{tabular}

and those without (20\% vs $39 \%, \mathrm{p}=0.09$ for NSAIDs use; $10 \%$ vs $9 \%, \mathrm{p}=0.85$ for other DMARDs use).

\section{Factors affecting MTX-PG concentrations}

To identify the individual patient factors affecting MTX-PG concentrations at weeks 12 and 24, correlation analyses of total MTX-PG concentrations with baseline patient characteristics including age, body weight, BMI, white cell count, red cell count, albumin level and eGFR were performed. The baseline BMI strongly affected total MTX-PGs at week $12(\rho=-0.318, p=0.006)$ and week $24(\rho=-0.422, p=0.002)$. Similar trends were observed for body weight $(\rho=-0.305, p=0.03)$ and serum albumin $(\rho=-0.422, p=0.002)$ at week 24 .

In order to verify the influence of BMI on the concentrations of MTX-PG, we divided 75 patients (no BMI data available in four patients) into three groups according to the BMI categories defined by the WHO: 12 underweight patients $\left(\mathrm{BMI}<18.5 \mathrm{~kg} / \mathrm{m}^{2}\right), 52$ normal weight patients $\left(18.5 \leq \mathrm{BMI}<25.0 \mathrm{~kg} / \mathrm{m}^{2}\right)$ and 11 overweight patients $\left(\mathrm{BMI} \geq 25.0 \mathrm{~kg} / \mathrm{m}^{2}\right)$. The total MTX-PG concentrations differed significantly among the three BMI groups (figure 3A). At week 24, the concentrations were found to be $151.6 \mathrm{nmol} / \mathrm{L}$ in the underweight group at $10.7 \mathrm{mg} /$ week of MTX, $92.1 \mathrm{nmol} / \mathrm{L}$ in the normal group at $10.9 \mathrm{mg} /$ week, and $65.6 \mathrm{nmol} / \mathrm{L}$ in the overweight group at $9.1 \mathrm{mg} /$ week $(p=0.001)$, while the $\triangle$ DAS28 at week 24 was comparable between the groups (-2.0 in the underweight group vs -1.7 in the normal group vs -1.8 in the overweight group, $\mathrm{p}=0.77$, figure 3B). Elevated transaminase levels (AST/ALT $\geq 100 \mathrm{IU} / \mathrm{L}$ ) were observed in $33.3 \%$ of the underweight group, $15.4 \%$ of the normal weight group and none of the overweight group $(\mathrm{p}=0.07$, figure $3 \mathrm{C})$. 


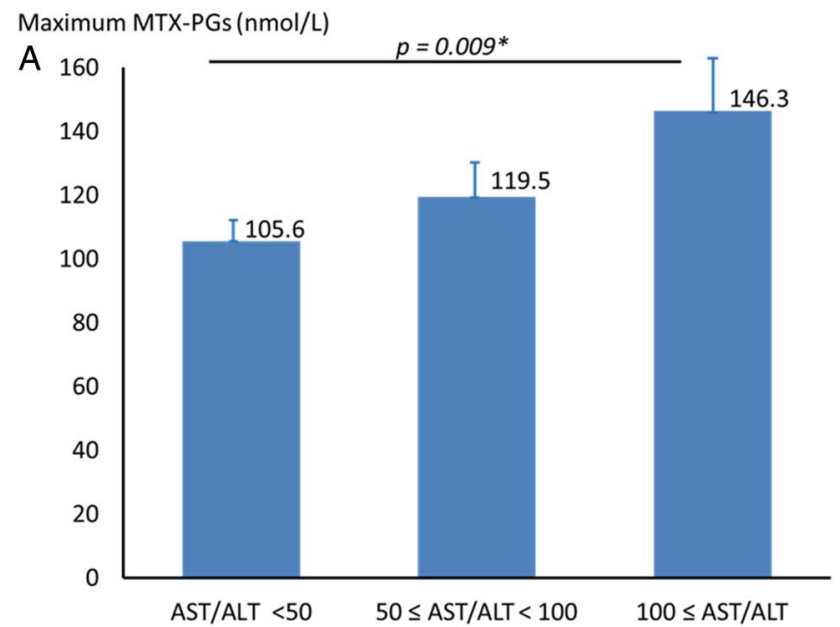

B

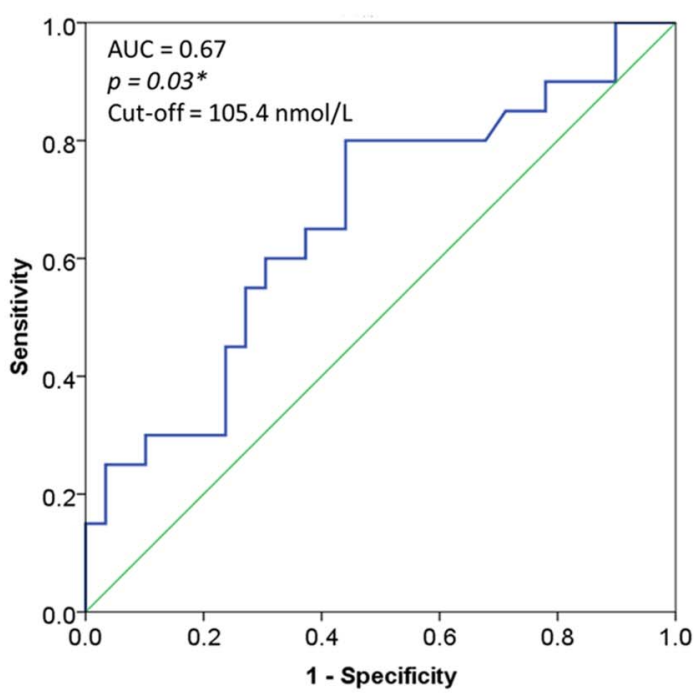

C

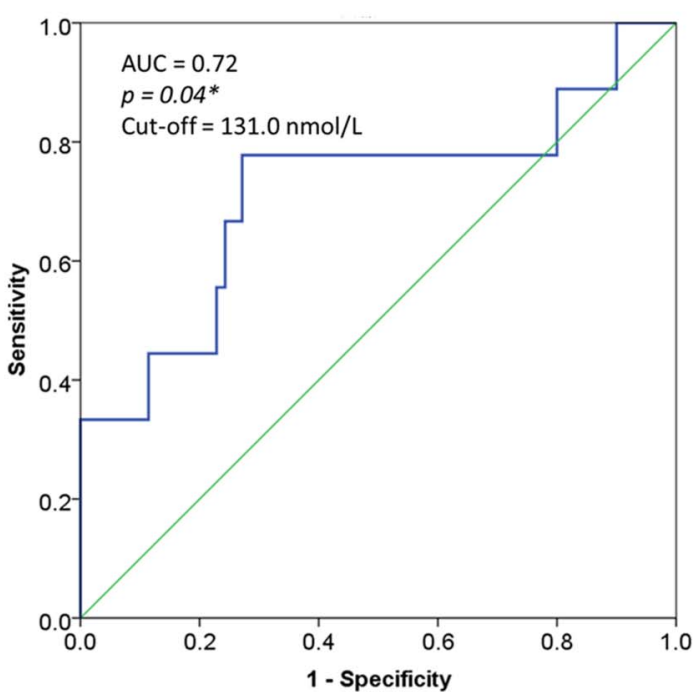

Figure 2 MTX-PG concentrations and hepatotoxicity. (A) Maximum MTX-PG concentrations among groups with or without hepatotoxicity; (B) cut-off values of total MTX-PG concentration for AST/ALT $\geq 50$ and (C) cut-off values of total MTX-PG concentration for AST/ALT $\geq 100$. ${ }^{*} p<0.05$. ALT, alanine transaminase; AST, aspartate transaminase; AUC, area under the curve; DAS28, Disease Activity Score for 28 joints; MTX-PG, methotrexate polyglutamate.
A MTX-PGs(nmol/L) $\quad p=0.001^{*}$

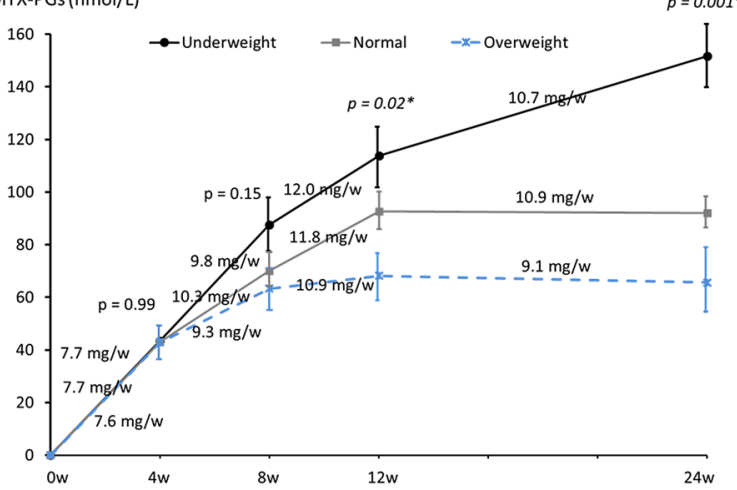

B
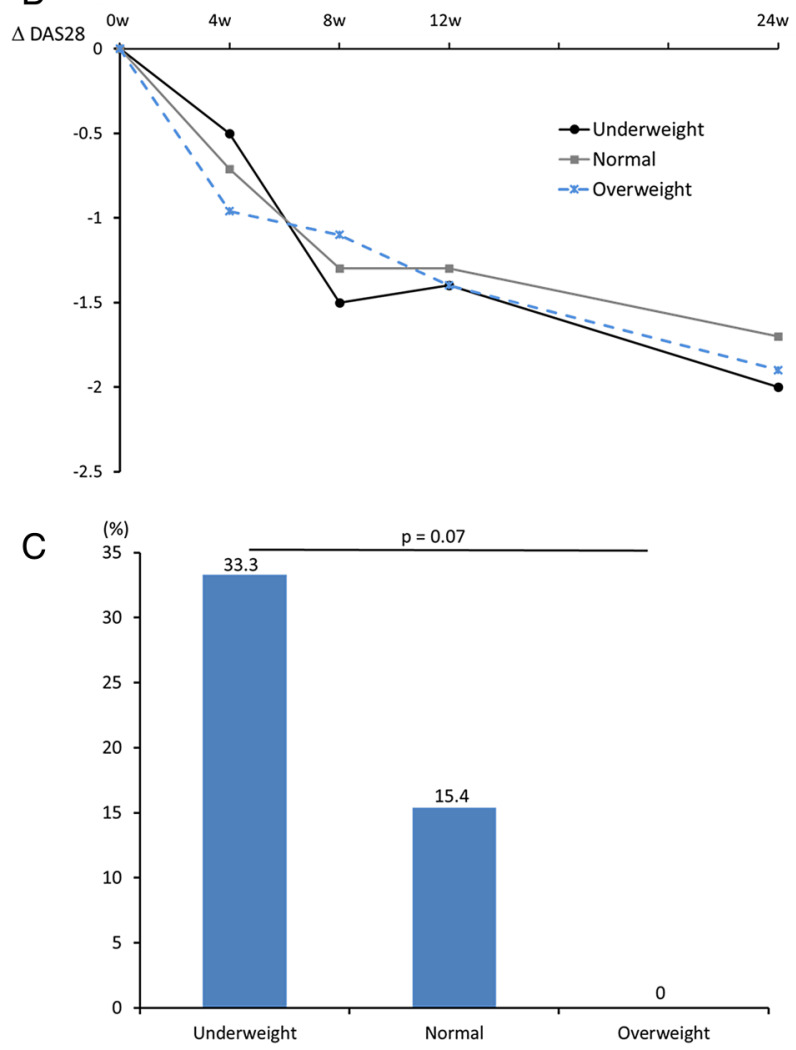

Figure 3 MTX-PG concentrations and BMI. (A) MTX-PG concentrations in the three groups divided according to the BMI category; (B) decrease in DAS28 in the three groups and (C) the frequency of $A S T / A L T \geq 100$. ${ }^{*} p<0.05$. ALT, alanine transaminase; AST, aspartate transaminase; BMI, body mass index; DAS28, Disease Activity Score for 28 joints; MTX-PG, methotrexate polyglutamate.

\section{DISCUSSION}

This prospective longitudinal cohort study revealed the utility of MTX-PG concentrations in assessing the efficacy and toxicity of MTX in patients with RA. We concluded that total MTX-PG concentrations between 83 and $105 \mathrm{nmol} / \mathrm{L}$ could be optimal for maximising the efficacy of MTX while minimising its toxicity in patients with RA. In addition, we have also identified the significant effect BMI has on MTX-PG concentrations. 
Associations between MTX-PG concentrations in erythrocytes and disease activity in patients with RA have been investigated in several studies. ${ }^{12-18}{ }^{21-24}$ Most of these studies have shown that higher MTX-PG levels were associated with lower disease activity, or that MTX-PG levels were significantly higher in patients responsive to MTX. Three longitudinal studies showed that an increase in MTX-PG concentrations was associated with a decrease in DAS28 scores. ${ }^{16} 2122$ The results of our longitudinal study in MTX-naïve Japanese patients with RA are consistent with those of previous studies, and we have added to the body of knowledge by showing that $83 \mathrm{nmol} / \mathrm{L}$ could be the threshold for a DAS28 improvement of $\geq 1.2$ by MTX. Although the relatively low mean DAS28 of 4.0 at baseline might be interpreted cautiously, we believe our results have provided new insights into the usage of MTX.

Little is known about the relationship of MTX-PGs and the safety of MTX. There have been a few reports indicating a relationship between adverse events and high MTX-PG3 to five levels in patients with juvenile idiopathic arthritis or inflammatory bowel disease. ${ }^{25} 26$ However, none of the MTX-PGs fractions have been linked to adverse events in patients with RA. ${ }^{21}$ Our findings have demonstrated the clear correlation between the MTX-PG levels and hepatotoxicity by showing that higher MTX-PG concentrations could result in higher transaminase levels. Although the maximum dose of MTX approved in Japan is $16 \mathrm{mg}$ /week, the mean MTX dose used in actuality remains $\sim 12 \mathrm{mg}$ /week owing to the predisposition of Japanese patients to adverse events. ${ }^{27}$ The frequent hepatotoxicity observed in our study clarified the relationship between MTX-PG concentrations and liver injury. Liquid chromatographyelectrospray ionisation tandem mass spectrometry used to measure MTX-PG levels may be disadvantageous in the cost and the practicality at the moment; nevertheless, monitoring MTX-PG concentrations can be helpful in clinical practice.

Interestingly, despite the dosages of MTX used being largely similar, the MTX-PG concentrations in our patients were markedly higher than those observed in other studies from Europe or the USA. Our samples were evaluated by Exagen using the exact same method reported by Dervieux et $a l^{21}$ who found that the total MTX-PGs at week 20 were around $65 \mathrm{nmol} / \mathrm{L}$ in patients with RA in the USA at $13.4 \mathrm{mg} /$ week of MTX. In contrast, our cohort, which comprised Japanese patients with RA, demonstrated MTX-PG concentrations of $94 \mathrm{nmol} / \mathrm{L}$ at $10.3 \mathrm{mg} /$ week of MTX at week 24 . The difference in MTX-PG concentrations could potentially be ascribed to the differences in physical frames. We found that BMI strongly affected MTX-PG concentrations, and that total MTX-PG concentrations were much higher in underweight patients despite the similar MTX dose. MTX-related pharmacogenomics may be another possibility. Several studies have indicated that MTX-PG concentrations may be influenced by polymorphisms in the genes encoding the enzymes and transporters involved in the import and export of MTX/MTX-PGs, and ethnic variations have been reported to influence the frequencies of these polymorphisms. ${ }^{28-30}$ Further studies are needed to investigate these polymorphisms in Japanese patients.

In conclusion, this study suggests that maintaining the MTX-PG concentrations in erythrocytes at $\sim 80$ $100 \mathrm{nmol} / \mathrm{L}$ could optimise treatment response while minimising liver injury in the treatment of RA with MTX. As such, monitoring MTX-PG concentrations can be helpful in clinical practice.

\section{Author affiliations}

${ }^{1}$ Division of Rheumatology, Department of Internal Medicine, Keio University School of Medicine, Tokyo, Japan

${ }^{2}$ Department of Internal Medicine and Center for Arthritis and Rheumatic Disease, Kawasaki Municipal Kawasaki Hospital, Kawasaki, Japan

${ }^{3}$ Department of Connective Tissue Diseases, Tokyo Medical Center, National Hospital Organization, Tokyo, Japan

Acknowledgements The authors would like to thank Ms Harumi Kondo and Ms Mayumi Ota for their assistance in the acquisition of clinical information.

Contributors CT, YK and TT designed the study and analysed and interpreted the data. $\mathrm{CT}, \mathrm{YK}, \mathrm{YO}, \mathrm{HT}, \mathrm{HO}, \mathrm{KI}$ and $\mathrm{KY}$ were involved in collecting data and managing the clinical research sites. All authors were involved in the writing of the manuscript and have approved the final version.

Competing interests YK has received lecture fees from Abbvie, Eisai Pharmaceutical, Chugai Pharmaceutical, Bristol Myers Squibb, Astellas Pharmaceutical, Mitsubishi Tanabe Pharma Corporation, Pfizer, Janssen and UCB. HO has received lecture fees from Astellas Pharma, Asahi Kasei, Takeda Pharmaceutical, Bristol Myers Squibb, MSD LLC, Chugai Pharmaceutical, Mitsubishi Tanabe Pharma Corporation and DS Pharma Biomedical Co. KY has received consulting fees and speaking fees from Pfizer, Chugai Pharma, Mitsubishi-Tanabe Pharma, Takeda Industrial Pharma, GlaxoSmithkline, Nippon Shinyaku, Eli Lilly, Janssen Pharma, Eisai Pharma, Astellas Pharma and Acterlion Pharmaceuticals. TT has received research grants and lecture fees from Abbvie, Astra Zeneca, Bristol Myers Squibb, Chugai Pharmaceutical, Eisai Pharmaceutical, Janssen Pharmaceutical, Mitsubishi Tanabe Pharma Corporation, Novartis, Takeda Pharmaceutical, Abbott Japan Co., Astellas Pharma, Daiichi Sankyo, Pfizer, Sanofi-Aventis, Santen Pharmaceutical, Teijin Pharma, Asahikasei Pharma Corp., SymBio Pharmaceuticals, Celtrion, Nipponkayaku Co., Eli Lilly Japan K.K. and Taisho Toyama Pharmaceutical.

Patient consent Obtained.

Ethics approval Keio University School of Medicine, Ethics committee.

Provenance and peer review Not commissioned; externally peer reviewed.

Data sharing statement No additional data are available.

Open Access This is an Open Access article distributed in accordance with the Creative Commons Attribution Non Commercial (CC BY-NC 4.0) license, which permits others to distribute, remix, adapt, build upon this work noncommercially, and license their derivative works on different terms, provided the original work is properly cited and the use is non-commercial. See: http:// creativecommons.org/licenses/by-nc/4.0/

\section{REFERENCES}

1. Smolen JS, Landewé $R$, Breedveld FC, et al. EULAR recommendations for the management of rheumatoid arthritis with synthetic and biological disease-modifying antirheumatic drugs: 2013 update. Ann Rheum Dis 2014;73:492-509.

2. Dervieux T, Brenner TL, Hon YY, et al. De novo purine synthesis inhibition and antileukemic effects of mercaptopurine alone or in combination with methotrexate in vivo. Blood 2002;100:1240-7. 
3. Morabito L, Montesinos MC, Schreibman DM, et al. Methotrexate and sulfasalazine promote adenosine release by a mechanism that requires ecto-5-nucleotidase-mediated conversion of adenine nucleotides. J Clin Invest 1998:101:295-300.

4. Cronstein BN, Naime D, Ostad E. The antiinflammatory mechanism of methotrexate. Increased adenosine release at inflamed sites diminishes leukocyte accumulation in an in vivo model of inflammation. J Clin Invest 1993;92:2675-82.

5. Godfrey C, Sweeney K, Miller K, et al. The population pharmacokinetics of long-term methotrexate in rheumatoid arthritis. Br J Clin Pharmacol 1998;46:369-76.

6. Hiraga $\mathrm{Y}$, Yuhki $\mathrm{Y}$, Itoh $\mathrm{K}$, et al. Pharmacokinetics and efficacy of low-dose methotrexate in patients with rheumatoid arthritis. Mod Rheumatol 2004;14:135-42.

7. Lebbe $\mathrm{C}$, Beyeler $\mathrm{C}$, Gerber $\mathrm{NJ}$, et al. Intraindividual variability of the bioavailability of low-dose methotrexate after oral administration in rheumatoid arthritis. Ann Rheum Dis 1994;53:475-7.

8. Ravelli A, Di Fuccia G, Molinaro M, et al. Plasma levels after oral methotrexate in children with juvenile rheumatoid arthritis. $J$ Rheumatol 1993;20:1573-7.

9. Hornung N, Ellingsen T, Attermann J, et al. MTX correlate to plasma concentrations and clinical efficacy. J Rheumatol 2008;35:1709-15.

10. Dalrymple JM, Stamp LK, O'Donnell JL, et al. Pharmacokinetics of oral methotrexate in patients with rheumatoid arthritis. Arthritis Rheum 2008;58:3299-308.

11. Bannwarth B, Pehourcq F, Schaeverbeke T, et al. Clinical pharmacokinetics of low-dose pulse methotrexate in rheumatoid arthritis. Clin Pharmacokinet 1996;30:194-210.

12. Hornung $\mathrm{N}$, Ellingsen $\mathrm{T}$, Attermann $\mathrm{J}$, et al. Patients with rheumatoid arthritis treated with methotrexate (MTX): concentrations of steady-state erythrocyte MTX correlate to plasma concentrations and clinical efficacy. J Rheumatol 2008;35:1709-15.

13. Angelis-Stoforidis P, Vajda FJ, Christophidis N. Methotrexate polyglutamate levels in circulating erythrocytes and polymorphs correlate with clinical efficacy in rheumatoid arthritis. Clin Exp Rheumatol 1999;17:313-20.

14. Dervieux T, Furst $D$, Lein DO, et al. Pharmacogenetic and metabolite measurements are associated with clinical status in patients with rheumatoid arthritis treated with methotrexate: results of a multicentred cross sectional observational study. Ann Rheum Dis 2005;64:1180-5.

15. Hobl EL, Jilma B, Erlacher L, et al. A short-chain methotrexate polyglutamate as outcome parameter in rheumatoid arthritis patients receiving methotrexate. Clin Exp Rheumatol 2012;30:156-63.

16. de Rotte MC, den Boer $\mathrm{E}$, de Jong $\mathrm{PH}$, et al. Methotrexate polyglutamates in erythrocytes are associated with lower disease activity in patients with rheumatoid arthritis. Ann Rheum Dis 2015;74:408-14.

17. Calasan MB, den Boer E, de Rotte MC, et al. Methotrexate polyglutamates in erythrocytes are associated with lower disease activity in juvenile idiopathic arthritis patients. Ann Rheum Dis 2015;74:402-7.
18. Aletaha D, Neogi T, Silman AJ, et al. 2010 Rheumatoid arthritis classification criteria: an American College of Rheumatology/ European League Against Rheumatism collaborative initiative. Arthritis Rheum 2010;62:2569-81.

19. van Gestel AM, Prevoo ML, van 't Hof MA, et al. Development and validation of the European League Against Rheumatism response criteria for rheumatoid arthritis. Comparison with the preliminary American College of Rheumatology and the World Health Organization/International League Against Rheumatism Criteria. Arthritis Rheum 1996;39:34-40.

20. van der Heijde DM, van 't Hof M, van Riel PL, et al. Development of a disease activity score based on judgment in clinical practice by rheumatologists. J Rheumatol 1993;20:579-81.

21. Dervieux T, Orentas LD, Marcelletti J, et al. HPLC determination of erythrocyte methotrexate polyglutamates after low-dose methotrexate therapy in patients with rheumatoid arthritis. Clin Chem 2003;49:1632-41.

22. Murosaki T, Nagatani K, Sato T, et al. Prediction of the therapeutic response to methotrexate at 24 weeks by methotrexatepolyglutamates concentration in erythrocytes at 8 weeks in patients with rheumatoid arthritis. Mod Rheumatol 2016. [Epub ahead of print 20 Jul 2016]. doi: 10.1080/14397595.2016.1208137

23. Dervieux T, Zablocki R, Kremer J. Red blood cell methotrexate polyglutamates emerge as a function of dosage intensity and route of administration during pulse methotrexate therapy in rheumatoid arthritis. Rheumatology (Oxford) 2010;49:2337-45.

24. Stamp LK, O'Donnell JL, Chapman PT, et al. Methotrexate polyglutamate concentrations are not associated with disease control in rheumatoid arthritis patients receiving long-term methotrexate therapy. Arthritis Rheum 2010;62:359-68.

25. Becker ML, Gaedigk R, van Haandel L, et al. The effect of genotype on methotrexate polyglutamate variability in juvenile idiopathic arthritis and association with drug response. Arthritis Rheum 2011;63:276-85.

26. Brooks AJ, Begg EJ, Zhang M, et al. Red blood cell methotrexate polyglutamate concentrations in inflammatory bowel disease. Ther Drug Monit 2007;29:619-25.

27. Atsumi T, Yamamoto K, Takeuchi T, et al. The first double-blind, randomised, parallel-group certolizumab pegol study in methotrexate-naive early rheumatoid arthritis patients with poor prognostic factors, C-OPERA, shows inhibition of radiographic progression. Ann Rheum Dis 2016;75:75-83.

28. Ranganathan P. An update on methotrexate pharmacogenetics in rheumatoid arthritis. Pharmacogenomics 2008;9:439-51.

29. den Boer E, de Rotte MC, Pluijm SM, et al. Determinants of erythrocyte methotrexate polyglutamate levels in rheumatoid arthritis. $J$ Rheumatol 2014;41:2167-78.

30. Ranganathan P, Culverhouse R, Marsh S, et al. Methotrexate (MTX) pathway gene polymorphisms and their effects on MTX toxicity in Caucasian and African American patients with rheumatoid arthritis. J Rheumatol 2008;35:572-9. 